former eould be released at some date earlier than sixteen weeks-the time one little girl, whom I saw at Stanmore, was occupied in her peeling. Strapping the feet with a plaster containing salicylic acid, or, as Dr. Jamieson suggests, resorcin, might help. Its known effects on corns and warts look promising. I must apologise for occupying your space, but the hope of inciting others with more valuable experience to communicate their views must be my excuse.

I am, Sirs, yours truly,

Twickenham, Sept. 19th, 1891. H. Howard MURPHY, M.D.

\section{GASTRO-ENTEROSTOMY FOLLOWED BY RECURRENCE OF SYMPTOMS.}

\section{To the Editors of The LANCET.}

SrRs, - I have read with much interest the report of Mr. F. C. Larkin's case of gastro-enterostomy, followed later by recurrence of symptoms for which jejunostomy was performed. In the remarks Mr. Larkin says: "There can be no doubt that the recurrence of gymptoms was due to elosure of the preternatural orifice. This closure might have occurred from one of two causes: (1) Extension of the malignant growth around and over the orifice; ('2) closure by cicatricial contraction." After carefully reading the case I am inclined to think that there may be a third cause for the recurrence of symptoms, which, I believe, will be Found to be the correct one-viz, constriction of the jejunum at the aperture in the transverse meso-colon or great omentnm, through which the intestine was drawn. That the extension of the malignant growth over the orifice may be found to be the cause is possible, but I do not think so probable as that the intestine was constricted or kinked.

The question as to the closure of the opening made between the stomach and jejunum in gastro-enterostomy is a most serious and important one. The only authentic case of closure of the opening by cicatricial contraction that has been reported, so far as I am aware, is Mr. Stansfield's. The case reported by Mr. Kilner Clarke, in which the symptoms returned-and he inferred that the opening had closed-he unfortunately was unable to confirm, as a post-mortem examination of the patient was not permitted. Personally I have performed gastro enterostomy five times, three successfully ; and once I have performed pylorectomy combined with gastro-enterostomy successfully (the report of this case will, with your permission, appear in your columns shortly), in none of these did any cicatricial contraction occur. Although one lived nine months after the operation, the two others are alive now, one eighteen months and the other eleven months since the operation of gastro.enterostomy. These patients take ordinary diet. The case of combined pylorectomy with gastro enterostomy has now been operated on seven weeks, and is being fed upon fish, minced meat, beeftea, eggs, and milk. She suffers no pain or discomfort after taking food. Experimentally I have performed a large number of operations for gastro-enterostomy, ileo-ileostomy, and ileo-colostomy; in no case have I ever found any cicatricial contraction. I therefore think we must look further than the gastro-jejunal opening for the cause of the obstruction in Mr. Larkin's case, and consider it will be found to be the result of one of the causes $I$ have mentioned.

One word as to the method employed by Mr. Larkin in performing so successfully the operation he has reported. I have anvocated and practised a method of uniting the jejunum to the posterior wall of the stomach through an opening in the transverse meso-colon; I have also made experiments in the same direction, but for reasons that would occupy too much of your space in this letter $I$ have abandoned it in favour of the ordinary method of fixing the intestine to the anterior wall of the stomach. I consider in those cases in which the disease in the stomach is so exten sive that it is difficult to find a suitable piece of healthy stomach to affix the intestine to, that jejunostomy performed in the way I have suggested, and which Mr. Larkin has so auceessfully performed in his case, is the only operation that is at all likely to give the patient relief.

I am, Sirs, yours very faithfully,

FREDK. Bowreman JessetT.

Upper Wimpole-street, Sept. 22nd, 1811.

\section{CHLOROFORM SYNCOPE. To the Editors of THE LANCET.}

SIRS - For those who do not require further pronfs that chloroform inhalation may cause syncope, cases like that of Dr. Rice in THE LANCET of Sept. 19th have an interest of a different kind. This springs from our desire to find out from such reports the modus operandi of the anæsthetic in producing this dreadful result, and for this purpose a non.fatal case is as importan as a fatal one. The report in this case, however, shows that there may be a radical difference of opinion as to the actual facts, which ought to be attended to and recorded. The report says not a word as to the moment when the administration was stopped. Was this done when the head was lowered and after the pupils had dilated, or was it done when the first observations on the pulse were made? If the latter, how much time elapsed while the several observations on the pulse were being made and before the pupil dilated? Apart from any theory as to the cause of syncope, it is an undeniable fact that it has often occurred some time after the inhalation has been stopped; and it is of the utmost importance to determine when such is the case, and when, if ever, the catastrophe may take place during the administration of a continuous atmosphere. It seems to follow as a necessary consequence from the terrible power of chloroform to cause syncope that the pulse must be watched. I beg to submit that this inference may be erroneous, and I utterly dissent from it. I believe that syncope is invariably the result of reaction from stopping the inhalation too soon, so that the chloroformist has only to go on with confidence, regardless of the pulse, the observation of which, indeed, may even give rise to a false alarm and drive him into the very danger he seeks to avoid. We may also ask if there were no interruptions to the administration in the above case before the dangerous symptoms set in? It is surely remarkable that three drachms of chloroform were expended without anresthetising the patient, and it is deserving of notice that the same thing is recorded in the last death from methylene and Junker's inhaler, and in which it is expressly stated that the inhaler was removed from time to time. We are told that anæsthesia may be maintained for an hour, and longer, with six drachms of methylene given by this inhaler, and that one drachm of chloroform is sufficient for an operation lasting ten minutes. If so, it would seem probable that breaks were allowed in the inhalation in the above case ; and at least I would beg to draw attention to the point as one which I believe to be of vital importance.

I am, Sirs, yours \&c.,

Partick, Glasgow, Sept. 22nd, 1891. ROBERT KIRK, M.D.

\section{CAP MARTIN : A NEW HEALTH STATION ON THE RIVIERA.}

To the Editors of THE LANCET.

SIRs,-At this time of the year, when so many people are forming plans for the winter, I should like to draw the attention of the profession to Cap Martin. As its name implies it is a small cape, running out in to the Mediterranean Sea between Mentone on the east and Monte Carlo on the west. It faces full south, and is far enough removed from the range of Maritime Alps behind to avoid those sweeping draughts which come down the valleys, and which are such serious drawbacks to Mentone and Nice. The whole estate is covered with pines, under which is a rich growth of underwood, consisting chiefly of myrtle and rosemary, making the air most fragrant and pleasant. When the estate is fully developed it will somewhat resemble the East Cliff at Bournemouth, only it will be set off with brilliant blues and greens instead of the alnost uniform depressing grey of Bournemouth in the winter. For cases requiring a still atmosphere Cap Martin will be very suitable, as under these trees even during aalf a gale the movement felt in the air is so slight that phthisical patients with a hæmorrhagic tendency and cardiac cases are able to go out and get their exercise in safety. Another important feature in Cap Martin is that it is level, thus differing from most other Mediterranean health stations.

The bistory of the place is this. About two or three years ago a Scotchman, Mr. Colvin White, bought the whole estate of about 200 acres. It was then a dense wood, used 